\title{
Small-Angle Neutron Scattering Study of High Fat Fish Oil-In-Water Emulsion Stabilized with Sodium Caseinate and Phosphatidylcholine
}

Yesiltas, Betül; Torkkeli, Mika; Almásy, László; Dudás, Zoltán; García Moreno, Pedro Jesús; Sørensen, Ann-Dorit Moltke; Jacobsen, Charlotte; Knaapila, Matti

\section{Published in:}

Langmuir

Link to article, DOI:

10.1021/acs.langmuir.9b03269

Publication date:

2020

Document Version

Publisher's PDF, also known as Version of record

Link back to DTU Orbit

Citation (APA):

Yesiltas, B., Torkkeli, M., Almásy, L., Dudás, Z., García Moreno, P. J., Sørensen, A-D. M., Jacobsen, C., \& Knaapila, M. (2020). Small-Angle Neutron Scattering Study of High Fat Fish Oil-In-Water Emulsion Stabilized with Sodium Caseinate and Phosphatidylcholine. Langmuir, 36(9), 2300-2306.

https://doi.org/10.1021/acs.langmuir.9b03269

\section{General rights}

Copyright and moral rights for the publications made accessible in the public portal are retained by the authors and/or other copyright owners and it is a condition of accessing publications that users recognise and abide by the legal requirements associated with these rights.

- Users may download and print one copy of any publication from the public portal for the purpose of private study or research.

- You may not further distribute the material or use it for any profit-making activity or commercial gain

- You may freely distribute the URL identifying the publication in the public portal 


\title{
Small-Angle Neutron Scattering Study of High Fat Fish Oil-In-Water Emulsion Stabilized with Sodium Caseinate and Phosphatidylcholine
}

\author{
Betül Yesiltas,* Mika Torkkeli,* László Almásy, Zoltán Dudás, Pedro J. García-Moreno, \\ Ann-Dorit M. Sørensen, Charlotte Jacobsen,* and Matti Knaapila*
}

Cite This: Langmuir 2020, 36, 2300-2306

Read Online

ACCESS | Lلll Metrics \& More | 回 Article Recommendations | st Supporting Information

ABSTRACT: We report on small-angle neutron scattering (SANS) investigations of separate phase domains in high fat (70\%) oil-in-water emulsions emulsified with the combination of sodium caseinate (CAS) and phosphatidylcholine (PC). The emulsion as a whole was studied by contrast variation to identify scattering components dominated by individual emulsifiers. The emulsion was subsequently separated into the aqueous phase and the oil-rich droplet phase, which were characterized separately. Emulsions produced with $1.05 \%(\mathrm{w} / \mathrm{w})$ CAS and PC fraction which varies between $1.75 \%(\mathrm{w} / \mathrm{w})$ and $0.35 \%(\mathrm{w} / \mathrm{w})$ provided droplets between 10 and $19 \mu \mathrm{m}$ in surface weighted mean in $70 \%$

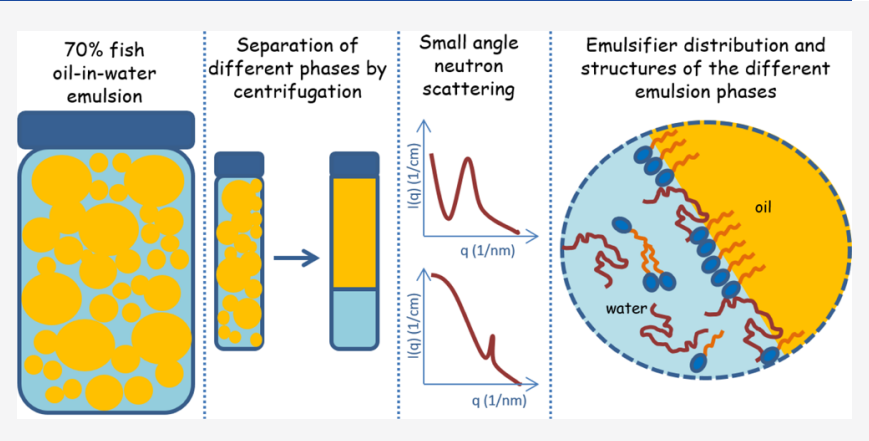
fish oil-in-water emulsions. At least two-third of the overall CAS is associated with the interface, while the rest remains with the aqueous phase. Six percent of PC formed a monolayer in the interface, while the rest of the PC remains in the droplet phase in the form of multilayers. When the separated components were resuspended, the resuspended emulsion showed similar characteristics compared to the original emulsion in terms of droplet size distribution and neutron scattering. Instead, CAS in the aqueous phase separated from the emulsion shows aggregation not present in the corresponding CAS-in- $\mathrm{D}_{2} \mathrm{O}$ system.

\section{INTRODUCTION}

Health benefits of marine long chain (LC) omega-3 polyunsaturated fatty acids (PUFAs) have been investigated in the last decades and beneficial health effects, such as decreasing cardiovascular diseases, reducing inflammation, and improving mental health, have been reported. ${ }^{1,2}$ During the last decade, fish oil-in-water emulsions have been used as delivery systems for increasing the intake of LC omega-3 PUFAs, such as eicosapentaenoic (C20:5n-3, EPA) and docosahexaenoic (C22:6n-3, DHA) acids. ${ }^{3,4}$ The fat content has a direct effect on the textural properties and viscosity of the emulsions and particular attention has been placed on the highest fat content. $^{4-7}$ High fat omega-3 delivery emulsions have advantage over low fat ones, as adding smaller amounts of delivery emulsion is adequate for enrichment. Moreover, high fat delivery emulsion has similar physical structure as the high fat foods (e.g., mayonnaise, high-fat dressings) and this provides easiness for mixing without significant alteration of the final product.

Casein has been investigated by researchers for decades and found to form a complex micellar structure with an average diameter of about $200 \mathrm{~nm}$ with a complicated association behavior. $^{8-11}$ Sodium caseinate (CAS) does not form micelles as milk casein but $10-11 \mathrm{~nm}$ sized particles, similar to submicelles formed by casein. ${ }^{12-14}$ Phosphatidylcholine (PC) has been used in the food industry as an emulsifier thanks to its surface active properties together with metal chelating and radical scavenging activities. PC forms a distinctive lamellar structure, when dispersed in water or oil-in-water emulsions above its critical micelle concentration. ${ }^{15}$

Oil-in-water emulsions can be stabilized by combining several emulsifiers, and this may allow better physical and oxidative stability compared to the use of a single emulsifier. ${ }^{16}$ This is not true for all emulsifier combinations as they may form separated domains at the oil-water interface, which may yield lower physical stability as well as oxidative stability due to the diffusion of prooxidants from one phase to another. ${ }^{17}$

We have recently studied the idea whereby a thicker oilwater interfacial layer may be formed and the better oxidative stability achieved by combining proteins and surfactants. ${ }^{18}$ If used as a single emulsifier, flexible and disordered proteins, such as casein, form a thicker but less dense interface

Received: October 21, 2019

Revised: February 13, 2020

Published: February 18, 2020 
compared to surfactants, which however can adsorb to the interface through the gaps in between the protein molecules. ${ }^{18-21}$ If emulsions are stabilized with the combined use of casein and surfactants (e.g., Tween 60 or lecithin), surfactants are assumed to replace some of the casein at the oil-water interface altering the characteristics of the adsorbed casein layer. $^{22-25}$ Lecithin, for example, may adsorb to the available hydrophobic areas at the oil-water interface, where there is a bare lipid surface in between casein molecules preventing aggregation and coalescence of the lipid droplets. ${ }^{2,23}$ Moreover, other studies also showed that proteins (CAS, $\beta$-casein, or $\beta$-lactoglobulin) were displaced by surfactants (Tween 20 , or Tween 60) and the growth of surfactants at the interface resulted in the compression and formation of more densely packed protein networks at the interface, which then lead to leave of the protein molecules in the bulk. ${ }^{26,27}$

In our previous paper, we focused on the interfacial properties on $70 \%$ oil-in-water emulsions stabilized with CAS and PC and characterized them using the combination of light scattering, small angle X-ray scattering and small angle neutron scattering (SANS). ${ }^{25}$ We found that the emulsions had $12-15$ $\mu \mathrm{m}$ sized droplets, the PC monolayer separating the oil and water phases. At the same time, $80 \%$ CAS was loosely bound to the interface without forming a continuous coverage. The distance between aggregated CAS in emulsion was increased compared to $\mathrm{CAS}$ aggregates in $\mathrm{CAS}-\mathrm{in}-\mathrm{D}_{2} \mathrm{O}$ system. The distance between PC bilayers became larger with increasing PC concentration. Multilayered PC (supposedly in the continuous aqueous bulk phase) became thicker in the presence of oilwater interface compared to the $\mathrm{PC}-\mathrm{in}-\mathrm{D}_{2} \mathrm{O}$. These findings pointed to the interaction or loose binding between the interface and multilayered PC. Focus was placed on the interface and conclusions were drawn from the overall emulsions and pure emulsifiers in water as well as from deuterated hexadecane, which was taken as a model compound for fish oil.

In this paper, we take another angle to our previous work placing focus on continuous aqueous and dispersed oil bulk phases. Moreover, we do not use deuterated hexadecane as a model compound for fish oil in this study. Fish oil contains several types of fatty acids including LC omega-3 PUFAs in triglyceride form, whereas hexadecane is an alkane hydrocarbon, which could represent only limited amount of fatty acids. Even though fish oil has strong incoherent scattering background in neutron scattering experiments, we decided to keep the original system for the sake of studying the original system, assuming fish oil's more complex interactions with emulsifiers compared to hexadecane during emulsion production. We identify the bulk phases in the overall mixture by SANS and contrast variation and subsequently separate and independently investigate followed by a re-suspension. This way we obtain information on the distribution of the emulsifiers in different phases of the emulsion as well as the re-dispersibility of the emulsion system after re-suspending the separated phases. This study contributes to understanding oilwater interfacial properties of high fat fish oil-in-water emulsions with implications in oxidative stability.

\section{MATERIALS AND METHODS}

Materials. Cod liver oil was provided by Maritex A/S (Sortland, Norway) and stored at $-40{ }^{\circ} \mathrm{C}$ until use. CAS (Miprodan 30) was donated by Arla Foods Ingredients amba (Viby J, Denmark). Arla reported a protein content of $92 \%$ in CAS for Miprodan 30. PC from soybean, PC (LIPOID S 100) was donated by Lipoid GmbH (Ludwigshafen, Germany). Specifications reported that PC content was $94.0 \%$ (based on dry weight). It also contained lysophosphatidylcholine not more than $3 \%$. Fatty acid $(\%, w / w)$ content of the PC was analyzed and determined as follows; C14:0 (0.09), C16:0 (12.55), C18:0 (3.77), C18:1n-9 (8.42), C18:2n-6 (65.82), C18:3n-6 (7.11). Deuterium oxide $\left(\mathrm{D}_{2} \mathrm{O}\right)(98 \% \mathrm{D})$ was purchased from Chemtronica (Stockholm, Sweden).

Figure 1 illustrates the estimated scattering length densities (SLDs) for the studied materials following the values reported in the

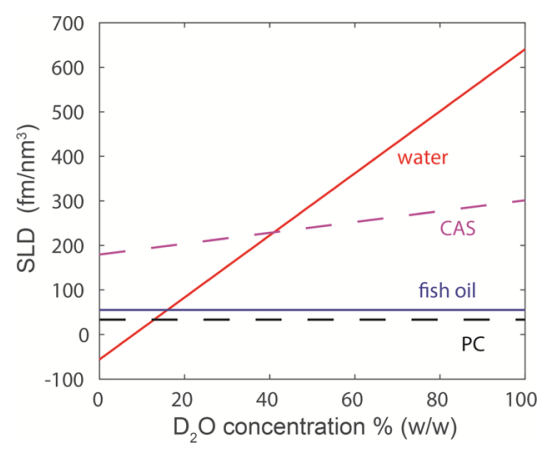

Figure 1. Illustration of employed SLD values for the aqueous matrix (red solid line), CAS (magenta dashed line), PC (black dashed line), and fish oil (blue solid line) against the $\mathrm{D}_{2} \mathrm{O} / \mathrm{H}_{2} \mathrm{O}$ ratio.

Supporting Information of Yesiltas et al. ${ }^{25}$ The SLD of water increases from that of $\mathrm{H}_{2} \mathrm{O}$ to that of $\mathrm{D}_{2} \mathrm{O}$ and the SLD of CAS increases because of the assumed hydrogen exchange with increasing $\mathrm{D}_{2} \mathrm{O}$ content. The SLD of PC and the SLD of fish oil are assumed constants. The latter was calculated for omega- 3 as $\mathrm{C}_{60} \mathrm{H}_{92} \mathrm{O}_{6}$.

Sample Preparation. The notation and sample compositions are listed in Table 1. Aqueous phases of the $70 \%(w / w)$ oil-in-water emulsions were prepared one day before and left overnight on the magnetic stirrer $(500 \mathrm{rpm})$ in order to allow the CAS and PC to dispersed together in distilled water or $\mathrm{D}_{2} \mathrm{O}$. Emulsions (10 g) were prepared neutral $\mathrm{pH} 7.0 \pm 0.1$ using hand-held Ultra-Turrax (POLYTRON PT 1200 E). First the aqueous phases were mixed for $30 \mathrm{~s}$ and then the oil phase was added slowly in $3 \mathrm{~min}$ while the aqueous phase was continuously mixed. After adding the oil phase, $70 \%$ oil-in-water emulsion was mixed for additional $4 \mathrm{~min}$. The amount of CAS and fish oil was fixed. The amount of PC and the composition of water were varied. This led to seven different emulsions in three different families in terms of PC fraction. These families are denoted as "a", "b," and "CAS".

Figure 2 illustrates the preparation of the oil-rich droplet phase and the water-rich aqueous phase. One of the original emulsions (EMULa-100) was separated into its aqueous phase and the oil-rich droplet phase using centrifugation at $36,000 \mathrm{~g}$ for $10 \mathrm{~min}$ at $10{ }^{\circ} \mathrm{C}$. After centrifugation was applied, two phases were obtained; droplet and aqueous phases. The droplet phase was collected with a spatula and the aqueous phase was collected using a needle connected to a syringe, which went into the bottom part of the tube. The droplet phase was mixed with pure $\mathrm{D}_{2} \mathrm{O}$ and re-suspended. This was repeated 3 times in order to make sure that the droplet phase was washed from unadsorbed emulsifiers (grey part marked in Figure 2). All the samples (i.e., the emulsions and separated components) were studied by SANS and the measurements were done within 3 days after sample preparation. No phase segregation was observed within this time.

Small-Angle Neutron Scattering. SANS measurements were performed on the Yellow Submarine instrument at the BNC in Budapest (Hungary). Samples were filled in Hellma quartz cells of 2 $\mathrm{mm}$ path length and placed in the instrument and the measurements were done at $25{ }^{\circ} \mathrm{C}$. The wavelengths of 4.38 and $10.23 \AA$ were used at the sample-to-detector distances of 1.15 and $5.25 \mathrm{~m}$ leading to the overall scattering vector $(q)$-range from 0.07 to $4.2 \mathrm{~nm}^{-1}$. A $10 \mathrm{~mm}$ diameter beam was used with $2 \mathrm{~mm}$ path length samples, contained in 
Table 1. List of Samples

\begin{tabular}{|c|c|c|c|c|c|c|c|c|c|}
\hline \multirow[b]{3}{*}{ code } & \multirow[b]{3}{*}{ sample } & & & \multicolumn{6}{|c|}{ bulk phases $\%(w / w)$} \\
\hline & & \multicolumn{2}{|c|}{ emulsifiers \% (w/w) } & \multicolumn{5}{|c|}{$\mathrm{D}_{2} \mathrm{O} / \mathrm{H}_{2} \mathrm{O}$} & \multirow[b]{2}{*}{ fish oil } \\
\hline & & CAS & PC & $0: 100$ & $20: 80$ & $40: 60$ & $70: 30$ & $100: 0$ & \\
\hline EMUL-a-0 & emulsion & 1.05 & 1.75 & 27.2 & & & & & 70 \\
\hline EMUL-a-40 & emulsion & 1.05 & 1.75 & & & 27.2 & & & 70 \\
\hline EMUL-a-100 & emulsion & 1.05 & 1.75 & & & & & 27.2 & 70 \\
\hline EMUL-b-0 & emulsion & 1.05 & 0.35 & 28.6 & & & & & 70 \\
\hline EMUL-b-20 & emulsion & 1.05 & 0.35 & & 28.6 & & & & 70 \\
\hline EMUL-b-40 & emulsion & 1.05 & 0.35 & & & 28.6 & & & 70 \\
\hline EMUL-CAS-0 & emulsion & 1.05 & & 29.0 & & & & & 70 \\
\hline EMUL-a-100-DP & \multicolumn{9}{|c|}{ droplet phase of EMUL-a- 100} \\
\hline EMUL-a-100-AP & \multicolumn{9}{|c|}{ aqueous phase of EMUL-a-100 } \\
\hline EMUL-a-100-RESUS & \multicolumn{9}{|c|}{ resuspension of EMUL-a-100-DP with $\mathrm{D}_{2} \mathrm{O}$} \\
\hline CAS 5\% “70:30” & solution & 5 & & & & & 95 & & \\
\hline CAS 5\% “100:0” & solution & 5 & & & & & & 95 & \\
\hline
\end{tabular}

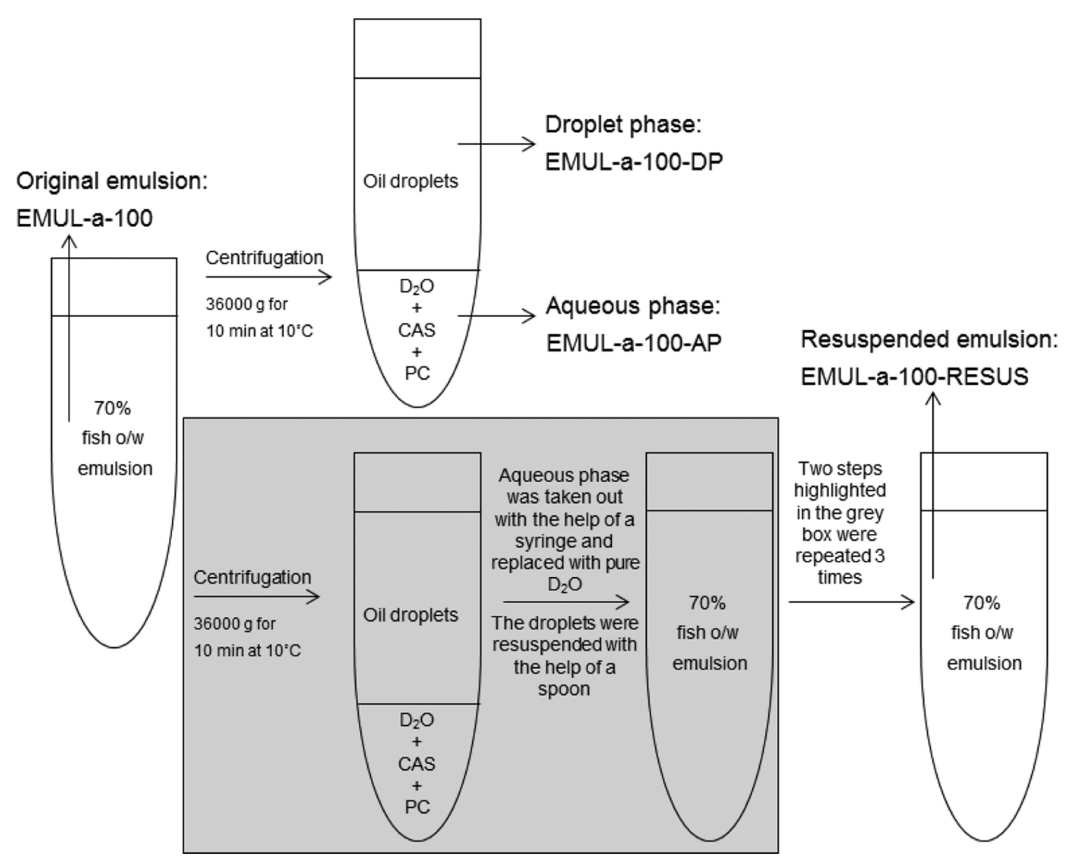

Figure 2. Illustration of sample preparation. "o/w emulsion" stands for "oil-in-water emulsion".

quartz cells, and with measurement times of 20-60 min. The used $\mathrm{D}_{2} \mathrm{O} / \mathrm{H}_{2} \mathrm{O}$ mixtures, empty cell and $\mathrm{H}_{2} \mathrm{O}$ were also measured. The scattering from the cell and solvent were subtracted from the data.

The scattering curves were calculated using the expanded Porod's law for two subsequent interfaces as in eq 1

$$
\begin{aligned}
I(q)= & \frac{S}{V}\left[\left(\rho_{\mathrm{e}}-\rho_{\mathrm{o}}\right)^{2}+\left(\rho_{\mathrm{e}}-\rho_{\mathrm{w}}\right)^{2}-2\left(\rho_{\mathrm{e}}-\rho_{\mathrm{o}}\right)\left(\rho_{\mathrm{e}}-\rho_{\mathrm{w}}\right)\right. \\
& \cos (q T)] \frac{2 \pi}{q^{4}}
\end{aligned}
$$

where $\rho_{\mathrm{e}}, \rho_{\mathrm{o}}$ and $\rho_{\mathrm{w}}$ are SLDs of emulsion interface, oil and water and where $S / V$ is the specific surface area. $T$ is the film thickness at the oil-water interface. The various contrast measurements were treated by assuming the same surface area but varying contrast of the water phase calculated for the given $\mathrm{D}_{2} \mathrm{O} / \mathrm{H}_{2} \mathrm{O}$ ratio.

The estimated contributions of free CAS in water were estimated for comparison (dashed curves, vide infra). These were based on experimental scattering profiles measured from CAS in $\mathrm{D}_{2} \mathrm{O}$ over 1$10 \%(\mathrm{w} / \mathrm{w})$ concentration range and the assumed concentrations were found by interpolation. ${ }^{25}$ In this process, the scattering intensities were scaled for the water phase volume and reduced scattering contrast as a function of $\mathrm{D}_{2} \mathrm{O} / \mathrm{H}_{2} \mathrm{O}$ ratio. This way, we were able to match the CAS and water content to the compared emulsions.

\section{RESULTS AND DISCUSSION}

Contrast Variation in Fish Oil-In-Water Emulsions. Figure 3 shows the droplet-size distribution of the studied high-fat emulsions stabilized with CAS and PC containing oil droplets within the aqueous phase. The distribution maximum corresponds to the previously reported $12 \mu \mathrm{m}$ droplet size of the emulsions produced with hexadecane. ${ }^{25}$ All the samples were stable during their measurement; no creaming or coalescence were observed. Droplet-size distribution of emulsions with two different formulae as well as before and after centrifugation and resuspension are shown in Figure S1, in the Supporting Information.

We next turn to the contrast variation considerations. The idea was to prepare $\mathrm{D}_{2} \mathrm{O} / \mathrm{H}_{2} \mathrm{O}$ mixtures that would make CAS and $\mathrm{PC}$ contributions selectively invisible to neutrons allowing us to obtain data dominated by one emulsifier (either PC or CAS) at a time. As shown in Figure 1, the first condition was 


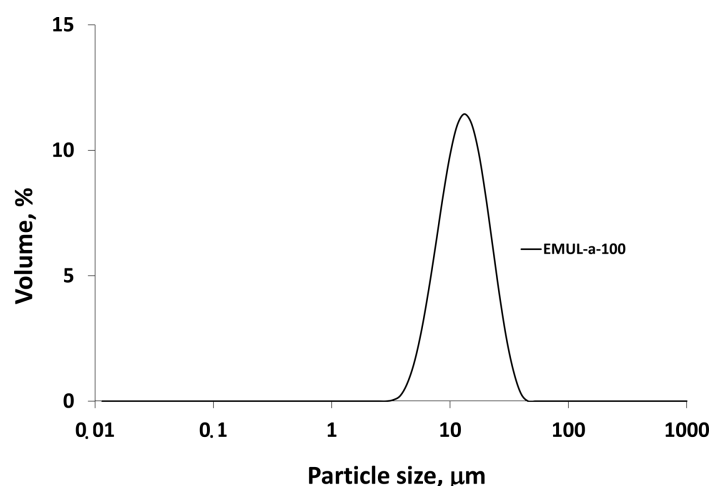

Figure 3. Droplet-size distribution of the studied high fat $(70 \%, w / w)$ oil-in-water emulsion produced with $1.05 \%$ CAS and $1.75 \%$ PC.

fulfilled in the 40:60 $\left(\mathrm{D}_{2} \mathrm{O} / \mathrm{H}_{2} \mathrm{O}\right)$ mixture, whereas the second condition was fulfilled in the 20:80 $\left(\mathrm{D}_{2} \mathrm{O} / \mathrm{H}_{2} \mathrm{O}\right)$ mixture.

Figure 4 shows the SANS patterns of the first emulsion family "a" with $1.05 \%(\mathrm{w} / \mathrm{w})$ CAS and $1.75 \%(\mathrm{w} / \mathrm{w})$ PC.

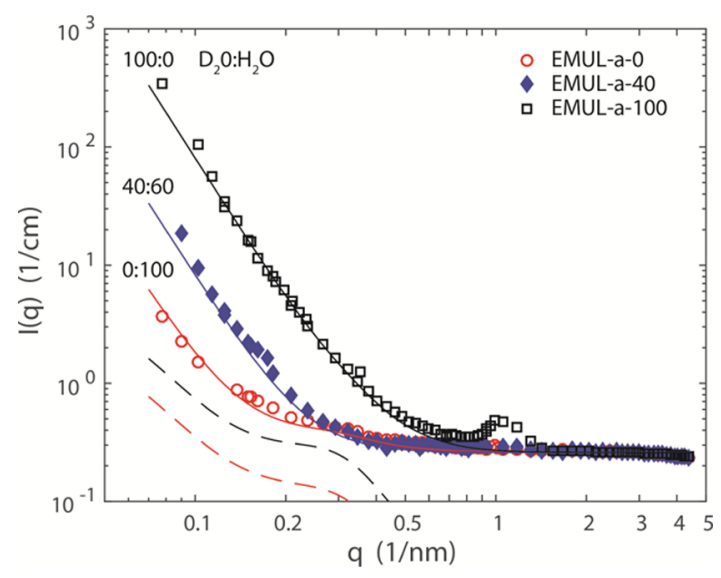

Figure 4. SANS patterns of the fish oil-in-water emulsions with the $\mathrm{D}_{2} \mathrm{O} / \mathrm{H}_{2} \mathrm{O}$ ratio as 0:100 (EMUL-a-0-red circles), 40:60 (EMUL-a40-blue solid diamonds), and 100:0 (EMUL-a-100-black squares). The solid lines are calculated scattering contributions for the interface with the PC monolayer together with free CAS. The dashed lines are calculated contributions for free CAS corresponding to equiv $1.05 \%$ $(\mathrm{w} / \mathrm{w})$ CAS concentration in a pure aqueous phase for 0:100 (dashed red line) and 100:0 $\mathrm{D}_{2} \mathrm{O} / \mathrm{H}_{2} \mathrm{O}$ ratios (dashed black line). The same contribution for $40: 60 \mathrm{D}_{2} \mathrm{O} / \mathrm{H}_{2} \mathrm{O}$ mixture falls below the plotted intensity scale.

Particular attention should be paid on the 40:60 mixture (EMUL-a-40) at this represents visible PC and invisible CAS and has not been discussed in our previous paper. ${ }^{25}$ The solid lines represent calculated scattering contributions for the given composition and contrast. The dashed lines represent estimated scattering contributions for free CAS in water for the discussed $\mathrm{D}_{2} \mathrm{O} / \mathrm{H}_{2} \mathrm{O}$ ratios.

The curve for the fish oil-in- $\mathrm{D}_{2} \mathrm{O}$ (EMUL-a-100) is similar to those reported in our earlier paper. ${ }^{25}$ It is dominated by the -4 slope for the lowest $q$, indicating the presence of globular particles, and shows a distinctive interference maximum at about $1 \mathrm{~nm}^{-1}$ originating from the scattering contrast within PC layers. The calculated scattering curves (solid lines) follows experimental data (symbols) apart from the interference maximum at $1 \mathrm{~nm}^{-1}$. This indicates that the system can be understood in terms of the above described 2-interface model (eq 1). This scattering contribution for free CAS in water (dashed lines) is an order of magnitude less than the interface contribution for fish oil-in-water systems showing how most of measured scattering arises from the interface.

To understand the overall intensities, we refer to the Figure 1 for contrast considerations. The higher the $\mathrm{D}_{2} \mathrm{O}$ fraction, the higher is the contrast between the oil phase and the aqueous phase. This explained increasing overall intensity with increasing $\mathrm{D}_{2} \mathrm{O}$ fraction regardless the match point between CAS and the aqueous phase (CAS is always a minority compound). The charged PC head incorporated water molecules and the observed PC peak for fish oil-in- $\mathrm{D}_{2} \mathrm{O}$ stems from the contrast between hydrogen rich $\mathrm{PC}$ and $\mathrm{D}_{2} \mathrm{O}$ incorporated into the PC layers. This peak is visible for the emulsion in $\mathrm{D}_{2} \mathrm{O}$ but disappears when the contrast between $\mathrm{PC}$ and $\mathrm{D}_{2} \mathrm{O}$ is suppressed for higher $\mathrm{H}_{2} \mathrm{O}$ concentrations, that is, for the 40:60 mixture.

The PC volume corresponds to $1.75 \%(\mathrm{w} / \mathrm{w})$ of the overall weight while the droplets counted as $70 \%$ of the overall weight. If we assume that the droplet radius was $6 \mu \mathrm{m}$ (Figure 3) and the monolayer thickness was $3.2 \mathrm{~nm}$ calculated from the molecule lengths, the monolayer volume would correspond to $0.1 \%$ of the overall volume. This means that approximately $6 \%$ of the originally incorporated PC would be located in the monolayer and the rest either in the bulk aqueous or bulk oil phase. In our previous paper, we studied multilayered PC particles in water and in the discussed emulsions. ${ }^{25}$ We found that the long period tended to be shorter and the coherence length (deduced from the peak width of Bragg reflections) was longer in emulsions, in the presence of interface. This pointed to a loose binding or a weak interaction between interface and multilayered PC. We could not quantify the exact amount of PC interacting with the interface.

The question is whether there is an equilibrium between PC located at the interface and PC located in the bulk or whether the PC monolayer is formed independently on free PC. This motivates us to decrease the PC content and move to the emulsion family " $b$ ", which is otherwise identical but has 5 times less PC than the family "a”.

Figure 5 plots the SANS patterns of the first emulsion family "b" with $1.05 \%(\mathrm{w} / \mathrm{w})$ CAS and $0.35 \%(\mathrm{w} / \mathrm{w})$ PC. Most interesting is to compare 20:80 mixture (EMUL-b-20), representing visible CAS and invisible $\mathrm{PC}$, to the data of 40:60 mixture (EMUL-b-40), representing visible PC and invisible CAS. The data of 20:80 mixture shows a shallow feature at $0.1-0.3 \mathrm{~nm}^{-1}$ originating from CAS. For the contrast reason, this feature is distinctive for 0:100 mixture (EMUL-b0 ) and for the emulsion without PC (EMUL-CAS-0). On the other hand, EMUL-b-40 shows a trace of PC peak at $1 \mathrm{~nm}^{-1}$ but this is significantly weaker than the peak associated with EMUL-a-100 (Figure 4). We assume that the major contribution to this maximum, which corresponds to the PC bilayer thickness, is due to associated water at the head to head layer. We suggest that the stronger peak stems from the higher contrast between relatively higher $\mathrm{D}_{2} \mathrm{O}$ fraction in the PC head domains and the higher PC overall concentration in EMUL-a100. As above, the relative scattering contributions from the corresponding amount of pure CAS in water (dashed lines) are well below those arising from the studied emulsions with the same $\mathrm{D}_{2} \mathrm{O} / \mathrm{H}_{2} \mathrm{O}$ ratios. When the emulsions in $\mathrm{H}_{2} \mathrm{O}$ are considered, EMUL-b-0 represents an emulsion where both emulsifiers are present and nominally visible (to the certain extent). The SANS pattern of pure CAS in oil-in- $\mathrm{H}_{2} \mathrm{O}$ 


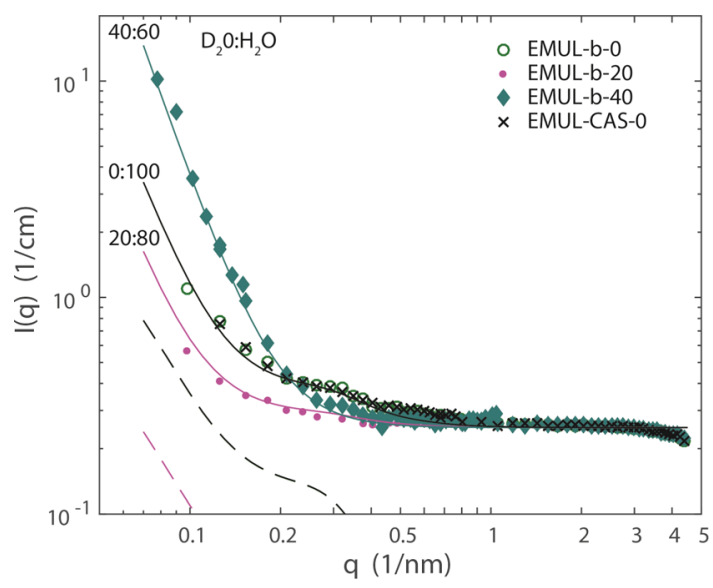

Figure 5. SANS patterns of the fish oil-in-water emulsions with the $\mathrm{D}_{2} \mathrm{O} / \mathrm{H}_{2} \mathrm{O}$ ratios as 0:100 (EMUL-b-0 - green circles), 20:80 (EMUL-b-20-magenta dots) and 40:60 (EMUL-b-40—cyan solid diamonds) alongside the data of the fish oil-in-water emulsified by pure CAS (EMUL-CAS-0-gray crosses). The solid lines are calculated scattering contributions arising from the interface together with free CAS. The dashed lines are calculated contributions for free CAS in $\mathrm{H}_{2} \mathrm{O}$ with and without PC (fully overlapping dashed green and black lines) and for the $20: 80 \mathrm{D}_{2} \mathrm{O} / \mathrm{H}_{2} \mathrm{O}$ mixture without $\mathrm{PC}$ (dashed magenta lines). The same contribution for 40:60 $\mathrm{D}_{2} \mathrm{O} / \mathrm{H}_{2} \mathrm{O}$ mixture without PC falls below the plotted intensity scale. These calculations correspond to the equivalent $1.05 \%(\mathrm{w} / \mathrm{w})$ CAS concentration in the pure aqueous phase. The $\mathrm{D}_{2} \mathrm{O} / \mathrm{H}_{2} \mathrm{O}$ ratios correspond to the plotted emulsion data.

emulsion (EMUL-CAS-0), that is emulsion without PC, is shown for comparison. Again, the overall scattering intensity increases with the increasing $\mathrm{D}_{2} \mathrm{O}$ fraction. The scattering contribution arising from PC in EMUL-b-0 is very small because of the similar SLD of fish oil and PC. The PC contribution is possibly seen in the latter case as a small maximum at $1 \mathrm{~nm}^{-1}$.

Separated Oil Rich and Aqueous Phases. We next move to the separated aqueous phase and the oil-rich droplet phase and their resuspension (cf., Figure 2). We assume that the aqueous phase contains $\mathrm{D}_{2} \mathrm{O}$ and any excess emulsifier preferring water not included at the oil-water-interface. In contrast, we assume that the droplet phase is a heavily concentrated oil-rich system containing oil droplets with the emulsifier interface and any excess emulsifier preferring oil.

Figure 6 shows the SANS patterns of the droplet phase (EMUL-a-100-DP) and the aqueous phase (EMUL-a-100AP). The corresponding data of the original fish oil-in- $\mathrm{D}_{2} \mathrm{O}$ emulsion (EMUL-a-100) alongside the data from the resuspended emulsion (EMUL-a-100-RESUS) are shown for comparison.

The data from the aqueous phase has no signs of the maximum at $1 \mathrm{~nm}^{-1}$ but instead a prominent feature at $0.1-$ $0.3 \mathrm{~nm}^{-1}$. The data from the droplet phase shows a distinctive maximum at $1 \mathrm{~nm}^{-1}$ but the feature at $0.1-0.3 \mathrm{~nm}^{-1}$ is diminished. This indicates that PC was associated with the droplet phase and the excess CAS with the aqueous phase. This also means that the observed maximum stems from both bulk and interface PC and is not a good measure for PC distribution. The scattering patterns of original emulsion and its resuspension are essentially similar being dominated by the -4 slope with an interference maximum at $1 \mathrm{~nm}^{-1}$ (an indication of PC) and a feature at $0.1-0.3 \mathrm{~nm}^{-1}$ (an indication

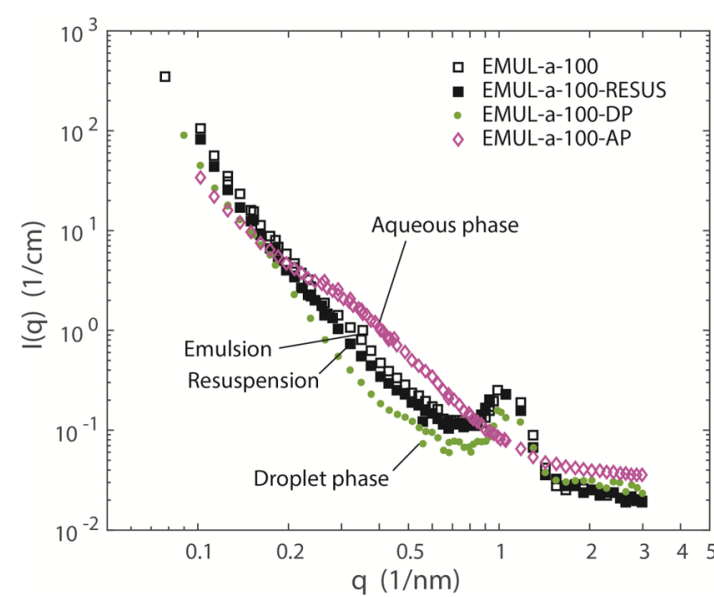

Figure 6. SANS patterns of fish oil-in- $\mathrm{D}_{2} \mathrm{O}$ emulsion (EMUL-a-100black open squares) and resuspended emulsion (EMUL-a-100RESUS - black solid squares) where the droplet phase was separated and resuspended in pure $\mathrm{D}_{2} \mathrm{O}$ three times (black solid squares) as well as a separated droplet phase (EMUL-a-100-DP-olive dots) and a separated aqueous phase (EMUL-a-100-AP-magenta diamonds).

of CAS). This implies that the separated components were resuspended and that the system was regained in colloidal length-scales.

Figure 7 shows the SANS pattern of the fish oil-in- $\mathrm{D}_{2} \mathrm{O}$ emulsion (EMUL-a-100) with the calculated data merged from

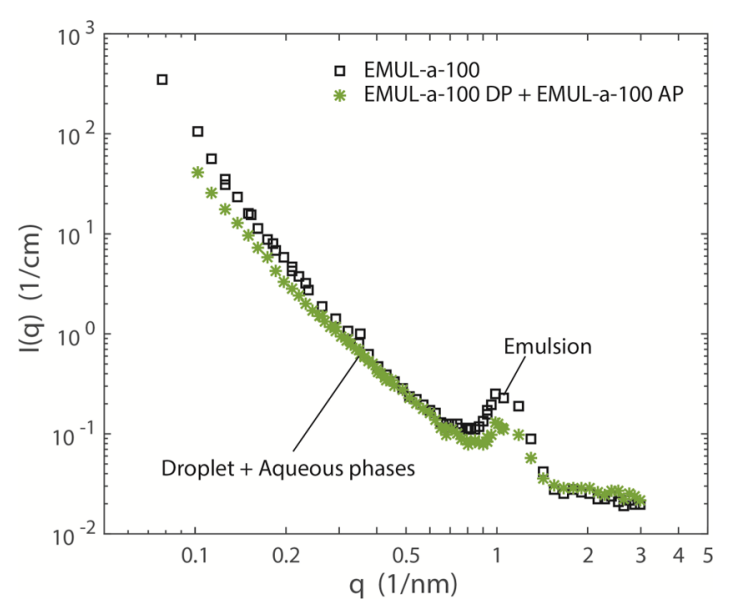

Figure 7. SANS patterns of fish oil-in- $\mathrm{D}_{2} \mathrm{O}$ emulsion (EMUL-a-100black squares) and the data calculated as a combination of separately measured data of the aqueous phase and the oil-rich phase (olive stars).

the scattering curves from the oil-rich droplet phase and the aqueous phase after separation. The merged data followed the emulsion data and replicates essential structural features of the original emulsion in the length scales probed by the instrument (about 1-60 nm). This indicates that the essential scattering features were maintained and no completely different structure is present in the separated droplet and aqueous phases.

Figure 8 shows the SANS patterns of the aqueous phase (EMUL-a-100-AP) alongside the data of $1 \%(\mathrm{w} / \mathrm{w})$ CAS and $2 \%(\mathrm{w} / \mathrm{w})$ CAS-in $-\mathrm{D}_{2} \mathrm{O}$ adapted from the ref 25 . All curves display a characteristic CAS feature, and the one observed for the aqueous phase corresponds to those observed for the 1$2 \%(\mathrm{w} / \mathrm{w})$ CAS-in- $\mathrm{D}_{2} \mathrm{O}$ data. By comparison, scattering characteristics of $5 \%(\mathrm{w} / \mathrm{w})$ CAS-in $-\mathrm{D}_{2} \mathrm{O}$ are more distinctive 


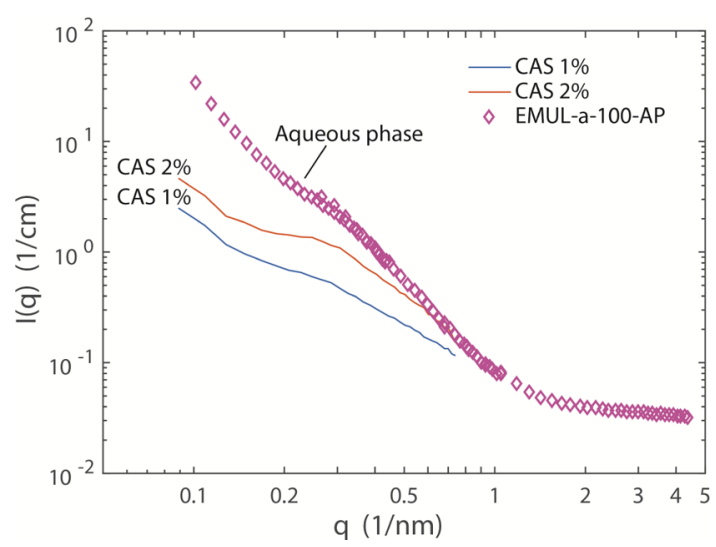

Figure 8. SANS patterns of the separated aqueous phase (EMUL-a100-AP-pink diamonds) compared with $1-2 \%$ CAS-in- $\mathrm{D}_{2} \mathrm{O}$ (solid lines). Two last curves were adapted from ref 25 .

(Figure S2, in the Supporting Information). Compared to the scattering curves from the CAS-in- $\mathrm{D}_{2} \mathrm{O}$, the curve from the aqueous phase has higher scattering intensity and an upturn at the lowest $q$. This indicates the presence of objects larger than present in aqueous CAS.

Using the data of the deuterated hexadecane-in- $\mathrm{D}_{2} \mathrm{O}$ emulsion, which was prepared to represent a model compound for the native fish oil-in- $\mathrm{D}_{2} \mathrm{O}$ emulsion, we argued that the most CAS was located at the oil-water interface and that the aqueous phase contained $22-23 \%(\mathrm{w} / \mathrm{w})$ of CAS placed in the emulsion in the first place. $^{25}$ This emulsion contained altogether $1.05 \%(\mathrm{w} / \mathrm{w})$ CAS against the overall weight which corresponds to $3.86 \%(\mathrm{w} / \mathrm{w})$ CAS against the $\mathrm{D}_{2} \mathrm{O}$ volume. If we assume that $22 \%(\mathrm{w} / \mathrm{w})$ of all CAS is located in $\mathrm{D}_{2} \mathrm{O}$, this would correspond to $0.22 \times 3.86 \%(\mathrm{w} / \mathrm{w})=0.85 \%$ $(\mathrm{w} / \mathrm{w})$ CAS-in- $\mathrm{D}_{2} \mathrm{O}$ system. This number matched well to the above-presented $1-2 \%(\mathrm{w} / \mathrm{w})$ CAS-in- $\mathrm{D}_{2} \mathrm{O}$ samples.

\section{CONCLUSIONS}

High-fat (70\%) oil-in-water emulsion was developed using a combination of CAS and PC. This emulsion was studied by SANS and contrast variation was employed to identify scattering components dominated by CAS or PC. The emulsion was subsequently separated into the aqueous phase and oil-rich droplet phase. Significant fraction of emulsifiers remained in the continuous bulk phases outside the interface. Approximately $70-80 \%$ of initial CAS was located at the interface and the rest in the aqueous phase. Circa $6 \%$ of initial PC formed a $3.2 \mathrm{~nm}$ thick monolayer at the interface. Rest of the $\mathrm{PC}$ remained in the droplet phase and in the close vicinity of the oil-water interface. Consequently, the droplet size distribution, as obtained by the laser diffraction, was insensitive to the total emulsifier concentration within the studied limits and remained similar when PC content was decreased from $1.75 \%(\mathrm{w} / \mathrm{w})$ down to $0.35 \%(\mathrm{w} / \mathrm{w})$. The separated aqueous and droplet phases appeared to be redispersible and similar to the original system over the length scales of 1-60 nm. CAS left in the continuous aqueous phase separated from the original emulsion formed scatterers larger than particles present in corresponding CAS-in- $\mathrm{D}_{2} \mathrm{O}$ mixtures. This indicated that the emulsion formation was not fully reversible.

In our previous work, we showed that the present CAS and PC combination and selected emulsifier fractions represented an optimum in terms of oxidative stability. ${ }^{18}$ The fact that a major part of emulsifiers remains in the bulk in this optimum might have implications when seeking for new emulsifier combinations and when planning work with additional antioxidants. In addition, it has been shown elsewhere that the oxidative stability depended on the droplet sizes and interfacial layer thickness and not only on the fatty acid composition. ${ }^{18,21,28}$ This implies that our structural ideas may be generalized to food matrices including various omega-3 polyunsaturated fatty acid compositions. Our future task includes using films as model systems as shown elsewhere for pure casein micelles. ${ }^{29}$

\section{ASSOCIATED CONTENT}

\section{S1 Supporting Information}

The Supporting Information is available free of charge at https://pubs.acs.org/doi/10.1021/acs.langmuir.9b03269.

\section{Additional SANS data (PDF)}

\section{AUTHOR INFORMATION}

\section{Corresponding Authors}

Betül Yesiltas - Division of Food Technology, National Food Institute, Technical University of Denmark, $2800 \mathrm{Kgs}$. Lyngby, Denmark; 이이.org/0000-0002-4587-9990; Email: betye@food.dtu.dk

Mika Torkkeli - Department of Physics, Technical University of Denmark, 2800 Kgs. Lyngby, Denmark; Email: mtork@ fysik.dtu.dk

Charlotte Jacobsen - Division of Food Technology, National Food Institute, Technical University of Denmark, $2800 \mathrm{Kgs}$. Lyngby, Denmark; 이이.org/0000-0003-3540-9669; Email:chja@food.dtu.dk

Matti Knaapila - Department of Physics, Technical University of Denmark, 2800 Kgs. Lyngby, Denmark; @ orcid.org/00000002-4114-9798; Email: matti.knaapila@fysik.dtu.dk

\section{Authors}

László Almásy - Neutron Spectroscopy Department, Centre for Energy Research, 1121 Budapest, Hungary; 이이. ord.org/0000001-5750-5788

Zoltán Dudás - Neutron Spectroscopy Department, Centre for Energy Research, 1121 Budapest, Hungary

Pedro J. García-Moreno - Division of Food Technology, National Food Institute, Technical University of Denmark, 2800 Kgs. Lyngby, Denmark; Department of Chemical Engineering, University of Granada, 18003 Granada, Spain

Ann-Dorit M. Sørensen - Division of Food Technology, National Food Institute, Technical University of Denmark, 2800 Kgs. Lyngby, Denmark

Complete contact information is available at: https://pubs.acs.org/10.1021/acs.langmuir.9b03269

\section{Notes}

The authors declare no competing financial interest.

\section{ACKNOWLEDGMENTS}

This study was supported by the Danish Council for Independent Research (DFF-4184-0123A and DFF-611100140B) and DANSCATT (7055-00005B).

\section{REFERENCES}

(1) Allaire, J.; Couture, P.; Leclerc, M.; Charest, A.; Marin, J.; Lépine, M.-C.; Talbot, D.; Tchernof, A.; Lamarche, B. A randomized, 
crossover, head-to-head comparison of eicosapentaenoic acid and docosahexaenoic acid supplementation to reduce inflammation markers in men and women: the Comparing EPA to DHA (ComparED) Study. Am. J. Clin. Nutr. 2016, 104, 280-287.

(2) Dobs, A. S.; Edelstein, D. Evaluating the Biological Activity and Effects on Human Health of Fish Oil and Its Omega-3 Fatty Acids. Wild-Type Food in Health Promotion and Disease Prevention; Humana Press Inc.: Totowa, NJ, 2008; pp 195-214.

(3) Jacobsen, C. Some strategies for the stabilization of long chain n3 PUFA-enriched foods: A review. Eur. J. Lipid Sci. Technol. 2015, 117, 1853-1866.

(4) Yesiltas, B.; García-Moreno, P. J.; Sørensen, A.-D. M.; Jacobsen, C. Physical and oxidative stability of high fat fish oil-in-water emulsions stabilized with combinations of sodium caseinate and sodium alginate. Eur. J. Lipid Sci. Technol. 2017, 119, 1600484.

(5) Horn, A. F.; Nielsen, N. S.; Andersen, U.; Sogaard, L. H.; Horsewell, A.; Jacobsen, C. Oxidative stability of $70 \%$ fish oil-in-water emulsions: Impact of emulsifiers and pH. Eur. J. Lipid Sci. Technol. 2011, 113, 1243-1257.

(6) Horn, A. F.; Nielsen, N. S.; Jacobsen, C. Iron-mediated lipid oxidation in $70 \%$ fish oil-in-water emulsions: effect of emulsifier type and pH. Int. J. Food Sci. Technol. 2012, 47, 1097-1108.

(7) Yesiltas, B.; García-Moreno, P. J.; Sørensen, A.-D. M.; Anankanbil, S.; Guo, Z.; Jacobsen, C. Effects of modified DATEMs with different alkyl chain lengths on improving oxidative and physical stability of $70 \%$ fish oil-in-water emulsions. J. Agric. Food Chem. 2018, $66,12512-12520$.

(8) Dalgleish, D. G. On the structural models of bovine casein micelles-review and possible improvements. Soft Matter 2011, 7, 2265-2272.

(9) Stothart, P. H.; Cebula, D. J. Small-angle neutron scattering study of bovine casein micelles and sub-micelles. J. Mol. Biol. 1982, 160, 391-395.

(10) Kumosinski, T. F.; Pessen, H.; Farrell, H. M.; Brumberger, H. Determination of the quaternary structural states of bovine casein by small-angle X-ray scattering: Submicellar and micellar forms. Arch. Biochem. Biophys. 1988, 266, 548-561.

(11) O'Connell, J. E.; Grinberg, V. Y.; de Kruif, C. G. Association behavior of beta-casein. J. Colloid Interface Sci. 2003, 258, 33-39.

(12) Thomar, P.; Nicolai, T. Dissociation of native casein micelles induced by sodium caseinate. Food Hydrocoll. 2015, 49, 224-231.

(13) Farrer, D.; Lips, A. On the self-assembly of sodium caseinate. Int. Dairy J. 1999, 9, 281-286.

(14) Smialowska, A.; Matia-Merino, L.; Ingham, B.; Carr, A. J. Effect of calcium on the aggregation behaviour of caseinates. Colloids Surf. A. 2017, 522, 113-123.

(15) Pichot, R.; Watson, R.; Norton, I. Phospholipids at the interface: Current trends and challenges. Int. J. Mol. Sci. 2013, 14, 11767-11794.

(16) McClements, D. J.; Bai, L.; Chung, C. Recent Advances in the Utilization of Natural Emulsifiers to Form and Stabilize Emulsions. Annu. Rev. Food Sci. Technol. 2017, 8, 205-236.

(17) Berton-Carabin, C. C.; Sagis, L.; Schroën, K. Formation, Structure, and Functionality of Interfacial Layers in Food Emulsions. Annu. Rev. Food Sci. Technol. 2018, 9, 551.

(18) Yesiltas, B.; García-Moreno, P. J.; Sørensen, A.-D. M.; Akoh, C. C.; Jacobsen, C. Physical and oxidative stability of high fat fish oil-inwater emulsions stabilized with sodium caseinate and phosphatidylcholine as emulsifiers. Food Chem. 2019, 276, 110-118.

(19) Dickinson, E. Faraday research article. Structure and composition of adsorbed protein layers and the relationship to emulsion stability. J. Chem. Soc. Faraday Trans. 1992, 88, 2973-2983.

(20) Munk, M. B.; Larsen, F. H.; van den Berg, F. W. J.; Knudsen, J. C.; Andersen, M. L. Competitive Displacement of Sodium Caseinate by Low-Molecular-Weight Emulsifiers and the Effects on Emulsion Texture and Rheology. Langmuir 2014, 30, 8687-8696.

(21) García-Moreno, P. J.; Horn, A. F.; Jacobsen, C. Influence of casein-phospholipid combinations as emulsifier on the physical and oxidative stability of fish oil-in-water emulsions. J. Agric. Food Chem. 2014, 62, 1142-1152.

(22) Fang, Y.; Dalgleish, D. G. Casein adsorption on the surfaces of oil-in-water emulsions modified by lecithin. Colloids Surf. B 1993, 1, 357-364.

(23) Dalgleish, D. G.; Srinivasan, M.; Singh, H. Surface properties of oil-in-water emulsion droplets containing casein and Tween 60. J. Agric. Food Chem. 1995, 43, 2351-2355.

(24) Waninge, R.; Walstra, P.; Bastiaans, J.; Nieuwenhuijse, H.; Nylander, T.; Paulsson, M.; Bergenståhl, B. Competitive Adsorption between $\beta$-Casein or $\beta$-Lactoglobulin and Model Milk Membrane Lipids at Oil-Water Interfaces. J. Agric. Food Chem. 2005, 53, 716724.

(25) Yesiltas, B.; Torkkeli, M.; Almásy, L.; Dudás, Z.; Wacha, A. F.; Dalgliesh, R.; García-Moreno, P. J.; Sørensen, A.-D. M.; Jacobsen, C.; Knaapila, M. Interfacial structure of $70 \%$ fish oil-in-water emulsions stabilized with combinations of sodium caseinate and phosphatidylcholine. J. Colloid Interface Sci. 2019, 554, 183-190.

(26) Mackie, A. R.; Gunning, A. P.; Wilde, P. J.; Morris, V. J. Orogenic Displacement of Protein from the Oil/Water Interface. Langmuir 2000, 16, 2242-2247.

(27) Woodward, N. C.; Gunning, A. P.; Mackie, A. R.; Wilde, P. J.; Morris, V. J. Comparison of the Orogenic Displacement of Sodium Caseinate with the Caseins from the Air-Water Interface by Nonionic Surfactants. Langmuir 2009, 25, 6739-6744.

(28) Lane, K. E.; Zhou, Q.; Robinson, S.; Li, W. The composition and oxidative stability of vegetarian omega- 3 algal oil nanoemulsions suitable for functional food enrichment. J. Sci. Food Agric. 2020, 100, 695-704.

(29) Metwalli, E.; Moulin, J.-F.; Gebhardt, R.; Cubitt, R.; Tolkach, A.; Kulozik, U.; Müller-Buschbaum, P. Hydration Behavior of Casein Micelles in Thin Film Geometry: A GISANS Study. Langmuir 2009, 25, 4124-4131. 